\title{
DINÂMICA GERACIONAL, POSIÇÕES SOCIAIS E COMPORTAMENTO POLÍTICO
}

\author{
KIMI TOMIZAKI ${ }^{1}$ \\ Maria Gilvania Valdivino Silva ${ }^{2}$
}

\begin{abstract}
RESUMO: Apresentamos, neste artigo, uma discussão de caráter eminentemente teórico, com implicações metodológicas, a respeito da formação e da transformação de opiniões, comportamentos e atitudes políticas a partir dos processos de transmissão e herança de posições sociais, ao longo do curso da vida. Assim, os comportamentos políticos, constituídos em função de múltiplas variáveis, seriam também determinados pela realização ou frustração de projetos intergeracionais de transmissão e herança de posições sociais, o que é vivenciado de modo diverso nas diferentes etapas da vida. Para tanto, apoiamos-nos em uma discussão com autores(as) franceses(as), em especial, Pierre Bourdieu, Annick Percheron e Anne Muxel, bem como no diálogo com a produção bibliográfica brasileira da última década sobre o tema.
\end{abstract}

Palavras-chave: Socialização política. Comportamento político. Gerações. Posições sociais. Idade.

\section{GENERATIONAL DYNAMICS, SOCIAL POSITIONS AND POLITICAL BEHAVIOR}

\begin{abstract}
Wepresent, in this paper, a discussion of an eminently theoretical character, with methodological implications, regarding the formation and transformation of opinions, behaviors, and political attitudes from the processes of transmission and inheritance of social positions, throughout the course of life. Thus, political behaviors, constituted according to multiple variables, would also be determined by the realization or frustration of intergenerational projects of transmission, and inheritance of social positions, which is experienced in different ways at different stages of life. To this end, we rely on a discussion with French authors, in particular Pierre Bourdieu, Annick Percheron and Anne Muxel, as well as on the dialogue with the Brazilian bibliographic production of the last decade on the subject.
\end{abstract}

Keywords: Political socialization. Political behaviour. Generations. Social positions. Age.

A discussão apresentada neste artigo é um desdobramento do projeto de pesquisa: Quando (Quase) Tudo se Desfaz: as Transformações do Comportamento Político da Categoria Metalúrgica do ABC Paulista e Suas Relações com Educação e Trabalho (Fapesp - Processo n. 2020/07727-7), sob coordenação de Profa. Dra. Kimi Tomizaki.

1.Universidade de São Paulo - Faculdade de Educação - São Paulo (SP), Brasil - E-mail: kimi@usp.br

2.Instituto Universitário de Lisboa - Centro de Investigação e Estudos de Sociologia - Lisboa, Portugal. E-mail: maria.gilvania@iscte-iul.pt Editor de Seção: Adriana Dragone Silveira 


\title{
DINÁMICA GENERACIONAL, POSICIONES SOCIALES Y COMPORTAMIENTO POLÍTICO
}

\begin{abstract}
RESUMEN: En este artículo presentamos una discusión de carácter eminentemente teórico, con implicaciones metodológicas, sobre la formación y transformación de opiniones, comportamientos y actitudes políticas a partir de los procesos de transmisión y herencia de posiciones sociales, a lo largo del curso de la vida. Así, los comportamientos políticos, constituidos por múltiples variables, también son determinados por la realización o frustración de proyectos intergeneracionales de transmisión y herencia de posiciones sociales, que se vive de manera diversa en las etapas de la vida. Para ello, nos apoyamos en una discusión con autores franceses, en particular, Pierre Bourdieu, Annick Percheron y Anne Muxel, y en el diálogo con la producción bibliográfica brasileña de la última década sobre el tema.
\end{abstract}

Palabras-clave: Socialización política. Comportamiento político. Generaciones. Posiciones sociales. Edad.

\section{Introdução}

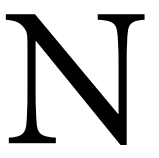

a medida em que os regimes democráticos são mais intensamente colocados em questão (e em risco), aumentam as demandas em torno da desafiadora tarefa intelectual e política de discutir quais são os efeitos dos processos educativos, especialmente a escolarização, sobre a formação dos comportamentos políticos dos cidadãos. Como já discutimos em publicações anteriores, acreditamos que os comportamentos políticos, ou, mais amplamente, os modos como indivíduos e grupos percebem e reagem a acontecimentos de "natureza política", podem ser considerados, entre outros fatores, também como resultado dos processos educativos desenvolvidos em variadas instâncias socializadoras (família, escola, trabalho, igreja, sindicatos, partidos, espaços associativos etc.). Portanto, para realizar a análise dos efeitos da educação sobre os comportamentos políticos, teríamos que realizar dois movimentos teóricos e metodológicos: 1) compreender a natureza e as características dos diferentes processos formativos de esquemas de percepção e avaliação da realidade de indivíduos e grupos; e 2) analisar os efeitos das conjunturas social, econômica e política, o que incluiria também as transformações do próprio campo político (TOMIZAKI; CARVALHO-SILVA; SILVA, 2016).

Neste artigo, tendo em vista adensar este debate, nos dedicaremos a apresentar uma discussão eminentemente teórica, com implicações metodológicas, sobre formação e transformação dos comportamentos políticos como parte dos processos de transmissão e herança de determinadas posições sociais. Portanto, assumimos a hipótese de que as perspectivas (individuais, familiares e de classe) em termos de possibilidades ou limites de reprodução ou alteração da posição social, e as estratégias a elas associadas, têm efeitos importantes sobre os processos educativos em geral e, portanto, também sobre a formação dos comportamentos políticos. Trata-se, assim, de uma abordagem pouco usual no Brasil, que relaciona tais comportamentos à realização ou à frustração de projetos intergeracionais de mobilidade ou conservação das posições sociais, o que pode ser vivenciado de modos muito diferentes dependendo da etapa da vida. Dito de outra maneira, discutiremos o desenvolvimento de opiniões, comportamentos e atitudes políticas ${ }^{1}$ a partir de duas dimensões que influenciam de modo importante os processos educativos e a relação com a política: 1) a transmissão e herança de posições sociais de indivíduo e grupos; e 2) as diferentes etapas da vida, ambas consideradas no âmbito da dinâmica das relações intergeracionais² . 
Para realizar esse exercício teórico, apoiamos-nos nas contribuições de diferentes autores(as), sobretudo em Pierre Bourdieu, Annick Percheron e Anne Muxel, cujas obras nos permitem sustentar a hipótese supracitada. Além disso, realizamos um diálogo com a produção bibliográfica brasileira da última década sobre o tema. Para tanto, foi realizada uma consulta junto à biblioteca eletrônica Scientific Eletronic Library Online do Brasil (SciELo Brasil) por meio das seguintes palavras-chave: "educação política"; "educação e política"; "educação e comportamento e política"; "educação para a democracia"; "socialização e política"; "socialização política”; “comportamento político"; "atitudes políticas”; "mobilidade social”. Após a leitura de todos artigos encontrados, selecionamos aqueles que dialogavam diretamente com o tema dessa publicação, o que totalizou 36 artigos e, com base nas citações dos(as) autores(as) desses artigos, incorporamos ainda três teses de doutorado e uma dissertação de mestrado.

No que tange a articulação entre as obras dos(as) autores(as) franceses(as) mencionados, é preciso destacar que tal debate exige, de um lado, que se considerem suas divergências e, de outro, a possibilidade de delineamento de uma zona de intersecção entre suas contribuições sobre o tema em questão. Nesse sentido, iniciamos pela discussão em torno da noção de socialização política, cuja especificidade é colocada em questão por Bourdieu, o qual, partindo da constatação de que há uma estreita relação entre ordem social e ordem política, não concebe que uma "educação política" possa existir de maneira independente dos processos "gerais" de produção das disposições, que constituiriam o fundamento dos julgamentos e das práticas políticas.

Se nem sempre observamos, entre a posição no espaço social e as opiniões políticas, relações simples e diretas quanto em outros domínios, é certamente neste campo, bem mais do que em qualquer outro, que o peso da trajetória social é muito importante na medida em que, através por exemplo da experiência de ascensão ou declínio, ela ordena toda a percepção do mundo social e, especialmente, do futuro deste mundo (BOURDIEU, 1977, p. 85).

Percheron, embora concordasse que não seria possível separar a socialização política dos demais processos de socialização, considerava factível apreender algumas especificidades dos processos de formação dos comportamentos políticos. Nesse sentido, a autora aponta que Bourdieu operaria com uma definição restritiva de política, discutindo prioritariamente as características e a dinâmica do campo político propriamente dito e as condições de formação das ditas "competências políticas" (que são também competências sociais) daqueles que se sentem ou não em condição de emitir suas opiniões sobre "assuntos políticos" (PERCHERON, 1993; BOURDIEU, 1977; 2011).

De acordo com Bourdieu, o espaço social é multidimensional e funciona como um macrocampo de forças (e de lutas), que abriga, em seu interior, uma multiplicidade de campos sociais mais específicos ${ }^{3}$, nos quais indivíduos e grupos se distribuem em função da posse de determinados capitais, que podem ser econômicos, culturais, sociais e simbólicos. Assim, alguns agentes, em função das posições que ocupam no espaço social, estão mais próximos de outros e, portanto, teriam maior probabilidade de internalizar disposições e tomadas de posição análogas, orientadas por um habitus ${ }^{4}$ de classe comum (BOURDIEU; WACQUANT, 1992). Nessa perspectiva, o campo político é o "lugar em que se geram - na concorrência entre os agentes que nele se acham envolvidos - produtos políticos, problemas, programas, análises, comentários, conceitos, acontecimentos, entre os quais os cidadãos comuns, reduzidos ao estatuto de 'consumidores', devem escolher" (BOURDIEU, 2005, p. 164). Logo, o campo político possui uma lógica e disputas internas próprias; no entanto, diferentemente de outros campos, ele nunca pode se autonomizar completamente, visto que depende do referendo dos votos para existir, o que o obriga a se remeter de diferentes maneiras aos "profanos" que detêm o poder (relativo) de determinar a composição e a organização do campo (BOURDIEU, 2005, p. 164). 
Em outro sentido, operando com uma concepção mais ampla da política, Percheron defendia que os estudos sobre a socialização política poderiam alcançar algumas especificidades dos "processos de construção do político" na vida cotidiana, por meio de pesquisas empíricas que abandonassem a ideia de um esquema único e homogêneo de socialização.

\begin{abstract}
Mesmos se os mecanismos fundamentais não mudam, os ritmos e os tempos fortes da socialização têm grandes chances de serem diferentes: a primeira infância, por exemplo, perderá sua importância em benefício da infância e da adolescência. Mesmo se os agentes principais continuam idênticos, suas ações correm o risco de não serem mais complementares [...]: em certo número de casos, por exemplo, a família e a escola poderão tornar-se agentes concorrentes até mesmo antagonistas. [...] Essas particularidades são suficientes para fundamentar a pertinência de um estudo sobre as condições de produção das representações e das práticas propriamente políticas (PERCHERON, 1993, p. 28).
\end{abstract}

Foi nesses termos que Percheron direcionou suas pesquisas à compreensão do universo político de crianças e adolescentes, o que lhe permitiu pensar a socialização política a partir de algumas premissas: 1) o socializado não é um ser passivo e toda socialização é o resultado da transação entre os indivíduos e a sociedade - assim, toda socialização comporta também "criação" e "escolhas", portanto jamais será uma simples reprodução; 2) a socialização é um processo, sempre inacabado, composto por etapas ligadas ao desenvolvimento afetivo e cognitivo dos indivíduos, às modificações no seu entorno e à diversidade de experiências; 3) a socialização política é uma dimensão de um processo mais amplo: a construção da identidade social - ou seja, a aquisição de códigos simbólicos de diversos grupos com os quais os indivíduos se identificam, podendo favorecer tanto a conformidade à ordem estabelecida quanto o desvio, a tradição ou as mudanças. Além disso, é preciso destacar a contribuição de Percheron para a análise da relação entre idade, efeitos de geração e atitudes políticas, que é prolongada e aprofundada nos trabalhos de Anne Muxel (MAYER, 1993; LAGROYE, 1994; DUBAR, 2002; MUXEL, 2011).

A partir dessas premissas, chegamos ao que parece ser uma segunda divergência importante entre Percheron e Bourdieu, a qual diz respeito à possibilidade de autonomia e criação dos próprios socializados no âmbito dos processos de socialização. É, portanto, preciso considerar as críticas dirigidas ao conceito de habitus, como definido por Bourdieu, como excessivamente rígido ou determinista, bem como à prevalência da socialização primária sobre os demais momentos da socialização. De fato, Bourdieu defende que a socialização primária cria "produtos" particularmente estáveis e resistentes à transformação, disposições irreversíveis, poderíamos dizer, ainda que não imutáveis. Nesse sentido, o habitus, embora tenha natureza durável, não constitui um conjunto de disposições cristalizadas, podendo ser reconfigurado em outras etapas da vida, em função das experiências com que os indivíduos são confrontados. No entanto, tais reconfigurações dependeriam de circunstâncias sócio-históricas muito específicas, marcadas pelo desencontro entre as condições de produção e as condições de funcionamento do habitus (BOURDIEU, 2009; DARMON, 2015; SINGLY, 2009; VANDENBERGHE; VÉRAN, 2016; VANDENBERGHE, 2016; LAHIRE, 2001).

De acordo com Peters (2013), na obra do sociólogo francês, com exceção do exercício da "autossocioanálise", apoiada pelo ferramental da sociologia, somente o descompasso entre as disposições dos agentes e seus ambientes de atuação/experiência possibilitariam o surgimento de ações fundadas na reflexão, o que negaria a possibilidade do processo inverso, ou seja, de que o exercício da reflexividade pelos atores redundasse em alterações na relação entre o habitus e a estruturação do espaço social. Assim, sem abrir mão do construto teórico de Bourdieu, o autor aponta os limites da noção de habitus no que tange a 
admissibilidade de que os atores possam ter um relativo controle reflexivo e consciente sobre suas próprias disposições práticas de conduta, fato que, inclusive, seria, em alguma medida, demonstrado pelo livro $A$ Miséria do Mundo, organizado por Bourdieu.

Mas o que um livro como A Miséria do Mundo também mostra é que, mesmo em situações em que não há, ao menos para todos os propósitos práticos, qualquer resistência à dominação estrutural e à distribuição desigual de recursos, a cumplicidade habitual dos dominados com a própria dominação que é observada no domínio da prática social pode coexistir com (e talvez até intensificar) uma experiência reflexiva, bastante consciente e, por vezes, discursivamente articulada de crítica aguda e rejeição dolorosa das próprias condições sociais de existência (PETERS, 2013, p. 62).

Assim, considerando tais críticas e também as contribuições de Bourdieu para a análise dos processos de transmissão de posições e disposições, neste artigo colocaremos em relevo o duplo movimento apontado nos estudos de Percheron e Muxel. De um lado, a afirmação da relevância dos mecanismos de transmissão e herança intergeracional de comportamentos políticos promovidos no âmbito familiar (considerados aqui em sua relação com a transmissão das posições sociais), que Muxel denomina "politização íntima”, cuja potência se localiza no fato de que as condições de transmissibilidade das escolhas políticas na família operam de modo implícito, por impregnação difusa, na qual são transmitidos valores e opiniões que impactarão as futuras experiências. De outro lado, a consideração de que, ao longo da vida, os comportamentos políticos passarão por ajustes e reajustes sucessivos, em função das circunstâncias (históricas, políticas, sociais ou biográficas) e dos encontros (pessoais e institucionais) que marcam o curso da vida, materializando-se em novas posições, escolhas e afiliações políticas (MUXEL; PERCHERON, 1985; PERCHERON, 1987; 1988; MUXEL, 2008; 2018).

\section{Comportamento Político e os Processos de Transmissão de Posições Sociais}

Se há um consenso no âmbito dos estudos geracionais, ele diz respeito ao fato de que as gerações mais velhas possuem grande propensão a criar estratégias para garantir a transmissão de suas posições sociais ou promover as condições para que as novas gerações alcancem posições que as primeiras gostariam de ter acessado; o que é expresso pelos pais pelo desejo de que seus filhos sofram menos ou encontrem menores dificuldades do que eles próprios (ATTIAS-DONFUT, 1988; 2000).

Assim, a mobilidade social intergeracional estrutura permanentemente as relações entre as gerações e ela orienta, notadamente, as formas e conteúdos das solidariedades familiares. Por exemplo, as transferências financeiras realizadas pelos pais aumentam se há risco de rebaixamento social dos filhos e o cuidado com os netos se intensifica para encorajar o avanço profissional das jovens mães (ATTIAS-DONFUT; WOLFF, 2001).

Nesse sentido, o estudo sobre as relações intergeracionais passa necessariamente pela discussão das possibilidades ou limites da mobilidade social que, de acordo com Attias-Donfut e Wolff (2001), deve abarcar tanto a dimensão objetiva das transmissões quanto a percepção subjetiva de diferenças ou semelhanças entre as posições sociais de pais e filhos, propondo, assim, a noção de "mobilidade social subjetiva", definida como o sentimento de ter sido bem ou malsucedido na vida em comparação com seus ascendentes e descendentes. 
Portanto, assumindo o papel central que a transmissão e a herança de posições sociais possuem nas relações intergeracionais, bem como nos modos como cada um consegue avaliar objetiva e subjetivamente "seu lugar" no mundo e no interior da sua linhagem (familiar e social), acreditamos ser impossível compreender adequadamente os processos de formação e transformação dos comportamentos políticos sem que esses sejam analisados à luz da realização ou frustração dos processos de transmissão intergeracional das posições sociais (TOMIZAKI, 2013; SILVA; TOMIZAKI, 2016).

Nesse sentido, vale salientar que não se trata de simplesmente relacionar a formação e a transformação dos comportamentos políticos com as condições de classe dos indivíduos e grupos em um dado momento fixo ou estático, mas de pensar tais processos de modo relacional e "em movimento". De acordo com Bourdieu, a sociedade pode ser definida como um espaço multidimensional de diferentes posições sociais, constituídas em função da distribuição das propriedades entre indivíduos e grupos, o que lhes confere poder nas relações com os outros. Tais propriedades são distintas formas de capital (econômico, cultural, social e simbólico), que devem ser analisadas, de um lado, por um recorte sincrônico da estrutura social - ou seja, a análise do volume e composição dos capitais de grupos e indivíduos - e, de outro lado, por um recorte diacrônico, que considera cada posição como um ponto específico da trajetória entre uma origem e um destino (BOURDIEU, 2005).

A posição social de um indivíduo ou de um grupo na estrutura social não pode jamais ser definida apenas de um ponto de vista estritamente estático, isto é, como posição relativa ("superior", "média" ou "inferior") numa dada estrutura e num dado momento. O ponto da trajetória que um corte sincrônico apreende contém sempre o sentido do trajeto social. Logo, sob pena de deixar escapar tudo que define concretamente a experiência da posição como etapa de uma ascensão ou de um descenso, como promoção ou regressão, é necessário caracterizar cada ponto pela diferencial da função que exprime a curva, isto é, por toda a curva (BOURDIEU, 2004, p. 8, grifos do autor).

Portanto, a posição social não pode ser definida somente pelo lugar ocupado por indivíduos e grupos na estrutura econômica, em sua relação com outras classes, ou estritamente pela posse de determinados capitais (econômicos, culturais, sociais e simbólicos). É preciso considerar o "sentido da trajetória" de cada indivíduo ou grupo (conservação, ascensão ou declínio), bem como suas avaliações objetiva e subjetiva das condições de possibilidade de manter ou alterar tal trajetória, o que redunda em modos específicos de constituir estratégias para o presente e projetos para o futuro que teriam efeitos importantes sobre comportamentos e posições políticas, na medida em que governos, instituições políticas, políticas públicas, partidos e até personagens políticos específicos (notadamente em cargos do Poder Executivo) podem ser concebidos como responsáveis pelas alterações nas condições de vida e no acesso a determinados bens e direitos.

Em artigo de 1978, Daniel Boy aponta que os efeitos da mobilidade social intergeracional sobre os comportamentos políticos dos indivíduos constituía já objeto de estudos, sobretudo nos Estados Unidos e na Inglaterra, desde os anos 1950 e que, em geral, tais estudos tendiam a concordar que os indivíduos que realizavam mobilidade social (ascendente ou descente) adotavam um comportamento político intermediário entre o "grupo de origem" e o "grupo de chegada". No entanto, o autor ressalta que estudos mais precisos dos mecanismos relacionados a esse fenômeno demonstram que os efeitos da origem social sobre o comportamento e as atitudes políticas não se relacionam somente com a distância entre a posição do pai e dos filhos, mas também segundo a natureza e as condições da trajetória social efetuada. Assim, diante das dificuldades de se estabelecer quantitativamente o peso das variáveis capazes de definir tais trajetórias, sobretudo no que diz respeito à "tradição política familiar", Boy aponta que estudos que relacionem comportamento político e classe 
social deveriam assumir uma perspectiva mais dinâmica, visto que o pertencimento de classe pode não se resumir somente à situação atual do indivíduo, comportando também a avaliação da sua posição em relação à posição dos seus pais, bem como sua "esperança social" - ou seja, a antecipação do seu futuro provável ou possível. Portanto, indo ao encontro da discussão das percepções objetiva e subjetiva da mobilidade social, Boy atenta para a necessidade de que as perspectivas de futuro, que podem ser de esperança ou frustração, sejam também consideradas nas análises sobre a mobilidade social entre gerações. Em estudos mais recentes, Peugny (2006; 2014), que se dedica à análise das consequências políticas da mobilidade intergeracional descendente entre assalariados na França, aponta que não há um efeito único e sistemático nesse processo, mas é possível perceber uma recomposição do universo axiológico desse grupo, no qual se destacam o sentimento de frustração que acompanha o declínio social; a transformação do discurso econômico (que congrega a crítica ao liberalismo econômico e o ataque aos "assistidos" pelas políticas públicas); e uma tendência ao voto na extrema direita.

Sem a pretensão de esgotar a discussão sobre um tema tão complexo, interessa-nos aqui destacar a relevância (e a necessidade) de estudos sobre os modos como os processos educativos, que medeiam as transmissões intergeracionais (inclusive dos modos de se relacionar com a política), são influenciados pelas avaliações objetivas e subjetivas que indivíduos e grupos fazem de suas trajetórias sociais em um jogo de espelhos entre o passado, o presente e as perspectivas de futuro.

$\mathrm{Na}$ análise da bibliografia nacional, é importante destacar que, especialmente na área de estudos da Educação, ainda há uma lacuna de pesquisas que tratem de modo mais específico e detalhado do papel dos processos de transmissão e herança intergeracionais na formação e na transformação dos comportamentos políticos de indivíduos e grupo. No entanto, importantes estudos, majoritariamente quantitativos e do campo das Ciências Políticas, lançam luz sobre uma série de correlações entre os comportamentos políticos da população brasileira, com destaque para o comportamento eleitoral, e diferentes dimensões da posição social, tais como renda, escolaridade, sexo, idade, nível de informação e efeitos geracionais (ROCHA, 2018; 2020; RENNÓ; BORBA, 2019; FUKS; CASALECCHI, 2018; FUKS; PAULINO; CASALECCHI, 2018; SILVA, 2019). Vale ainda destacar que, na última década, as pesquisas sobre comportamento político no Brasil foram fortemente marcadas pela discussão em torno dos efeitos da diminuição das desigualdades e da pobreza, bem como do surgimento e do enfraquecimento do lulismo ${ }^{5}$, relacionado, entre outros fatores, ao ascenso do antipetismo (SAMUELS, 2004; TERRON; SOARES, 2010; BORGES; VIDIGAL, 2018; RIBEIRO, 2011; RIBEIRO; CARREIRÃO; BORBA, 2016).

No que tange o papel da classe social na constituição dos comportamentos políticos, os estudos brasileiros tendem a confirmar a pertinência dessa variável, apontando inclusive para inflexão na literatura acadêmica sobre as relações entre voto e classe social, que passa a revalorizar a classe social como fonte de orientação do voto, contrariando o consenso estabelecido ao longo dos anos 1980 e 1990 sobre a perda de importância do pertencimento de classe como variável explicativa do comportamento eleitoral em democracias avançadas. Nesse mesmo sentido, outros estudos discutem como a percepção de ascendência social ou de melhora na situação econômica das famílias é determinante na definição do voto (FERRAZ, 2009; PEIXOTO; RENNÓ, 2011; RENNÓ; TURGEON, 2016).

Em relação aos efeitos da escolarização sobre o comportamento político, Dias e Kerbauy (2015), ao analisar as eleições presidenciais de 2014, concluem que a escolaridade é uma variável capaz de influenciar o comportamento do cidadão e, embora o interesse e a participação política no Brasil sejam muito baixos, os mais escolarizados se mostram mais interessados, informados e participativos. Além disso, são os mais escolarizados que tendem a apoiar as instituições políticas e a democracia como melhor forma de governo. No entanto, neste mesmo grupo são encontrados os maiores índices de insatisfação com o funcionamento da 
democracia no Brasil e até mesmo declarações de apoio a regimes ditatoriais em circunstâncias específicas, como crises econômicas ou políticas. Ainda sobre a questão dos efeitos da escolarização, é importante considerar o trabalho de Schlegel (2010), o qual aponta que a correlação entre aumento de escolaridade e valorização da democracia vinha perdendo força na última década no Brasil, destacando a necessidade de se considerarem outras dimensões do acesso à escola, tais como a qualidade do ensino, os efeitos geracionais e o ambiente educacional.

Assim, esses estudos demonstram que os efeitos dos processos educativos sobre a constituição dos comportamentos políticos, entre eles a escolarização, não possuem uma lógica inequívoca, o que exige que tais processos sejam discutidos na relação com outras variáveis, como as posições sociais, as conjunturas política e econômica e as culturas políticas. Destacam-se, nesse sentido, as pesquisas que discutem a adesão ambivalente da população brasileira em relação ao regime democrático, visto que é possível registrar certa incongruência entre a afirmação de que a democracia seria a melhor forma de governo e a desvalorização de práticas e princípios democráticos (tais como eleições livres e diferentes formas de participação política). As pesquisas ainda apontam que o desenvolvimento econômico, a diminuição das desigualdades, o bom funcionamento do regime democrático e a longevidade da experiência democrática são fundamentais para o desenvolvimento da "coesão democrática"; ou seja, a formação de um "sistema de crenças" democrático coerente, no qual atitudes e opções de voto convergem para o apoio dos princípios e valores democráticos (GIMENES; BORBA, 2019; FUKS, CASALECCHI; RIBEIRO, 2019; FUKS et al., 2016).

Sem dúvida alguma, a partir dos estudos brasileiros, podemos acessar dados significativos sobre as características dos comportamentos políticos dos(as) brasileiros(as), suas nuanças e contradições, além da diversidade teórica e metodológica desse tipo de estudo. No entanto, ainda nos dedicamos pouco à compreensão dos mecanismos de formação de tais comportamentos, o que provavelmente exigiria mais pesquisas qualitativas, além de recortes mais precisos quanto à posição social (em suas dimensões objetiva e subjetiva) e suas implicações nos modos de vida e de percepção da realidade de indivíduos e grupos.

\section{Comportamento Político ao Longo da Vida: Continuidades e Rupturas}

A partir da discussão realizada anteriormente sobre a importância dos processos de transmissão de posições sociais na formação e na transformação dos comportamentos políticos, nesta seção discutiremos como tais processos são vivenciados de modo diverso por indivíduos e grupos em diferentes etapas da vida, visto que, a partir de distintos "lugares" na relação entre gerações, os indivíduos podem perceber e avaliar, de modo divergente, as possibilidades de realização dos projetos intergeracionais, o que também é influenciado pela nuance das idades. De acordo com Ortega y Gasset, é preciso distinguir duas noções no estudo das gerações: a contemporaneidade e a igualdade de idade, visto que coexistem nas sociedades indivíduos contemporâneos que pertencem a gerações diferentes e, portanto, percebem os acontecimentos com diferentes "tonalidades", constituídas em função da idade (ORTEGA y GASSET, [1923]1981).

Nesse sentido, a noção de idade, que Percheron (1993) definia como a condensação, em uma mesma noção abstrata, de trajetórias biológicas, sociais e afetivas, tem lugar importante na discussão das etapas da vida; e, mesmo considerando que não existam "efeitos puros" de idade sobre os comportamentos políticos, não resta dúvida de que não podemos ignorar tal dimensão. Assim, a idade introduz na análise dos comportamentos políticos o parâmetro fundamental do tempo e da duração da existência, mesmo que seu papel na estruturação e na evolução das atitudes e dos comportamentos políticos não seja regular nem facilmente identificável. Segundo Muxel (2011), alguns demógrafos consideram a idade uma "variável 
intermediária”, nem dependente, nem independente: uma variável que reforça ou atenua os efeitos de outras variávies consideradas mais decisivas. Assim, a autora propõe que a idade seja considerada em um quadro mais amplo e complexo, a partir de três escalas temporais: a "idade-período" (temporalidade histórica); "a idade-geração" (temporalidade geracional); e a "idade-biografia” (temporalidade individual).

Dessa maneira, tendo em conta a complexidade das escalas temporais envolvidas no desenvolvimento das etapas da vida, consideramos particularmente operacional a noção de curso de vida, que, segundo Alwin, Felmlee e Kreager (2018), refere-se ao conjunto de caminhos interligados percorridos por um indivíduo ao longo da vida em diferentes domínios - por exemplo, a família, o sexo, a raça, a religião, além do local de nascimento e moradia, do trabalho, dos condicionantes econômicos, entre outros. Tais caminhos, por sua vez, seriam marcados por sequências de acontecimentos nas diferentes etapas da vida (biológica e social), desde o nascimento até a morte. Evidentemente, as transições e exposições aos diferentes acontecimentos pelos quais os indivíduos passam não seriam iguais para todos, visto que dependeriam de outras variáveis, como os condicionantes de classe social, o período histórico e a organização societária (ALWIN; FELMLEE; KREAGER, 2018; BERNARDIA; HUININKB; SETTERSTEN; 2019; ELDER; GIELE, 2009).

Parte considerável dos estudos sobre o curso de vida se concentra em uma fase da vida ou na transição entre duas fases, com grande destaque para a transição da juventude à vida adulta; tais estudos compõem a chamada perspectiva do curso de vida (NICO, 2011; ALWIN; FELMLEE; KREAGER, 2018). Assim, como é possível deduzir, "o tempo (ou a temporalidade) é fundamental para a perspectiva do curso de vida, devendo ser considerado como unidade de resgistro individual, social e histórico” (NICO, 2011, p. 14). Os indivíduos percorreriam, portanto, diferentes caminhos interligados em cada fase de sua vida, nos quais se desenvolvem os diferentes processos de socialização e, nesse sentido, acreditamos que a utilização da perspectiva do curso de vida pode ser particularmente útil para a compreensão dos comportamentos políticos, pois os caminhos percorridos pelos indivíduos promovem experiências e expectativas nuançadas pelas etapas da vida, bem como pelos desafios que cada uma delas impõe aos indivíduos e aos processos de transmissão e herança.

$\mathrm{Na}$ análise da bibliografia nacional identificamos que, de maneira geral, os trabalhos que discutem a relação entre processos de socialização política, participação política e as etapas da vida o fazem por meio do foco em uma fase específica, com destaque para a juventude - o que, por sua vez, estaria mais próximo da perspectiva do curso de vida, embora nem sempre fique claro com qual definição de idade, etapa da vida ou geração os(as) autores(as) estão operando.

Iniciando pela infância, podemos afirmar que estudos sobre as relações entre as crianças e a política não são comuns não somente no Brasil, sobretudo do ponto de vista da participação política na infância. De acordo com Muxel (2018), há uma tendência à sacralização da infância em contraponto com a imagem negativa da política e, portanto, os pais tendem a considerar que os posicionamentos políticos devem ser adquiridos de forma autônoma e, preferencialmente, depois da infância. Ao mesmo tempo, a maioria dos pais considera que a educação política deve ser uma preocupação familiar e não escolar ${ }^{6}$. No entanto, as pesquisas desenvolvidas por Annick Percheron $(1974$; 1993) indicam que crianças apreendem elementos do universo político desde muito cedo, por meio da transmissão implícita de opiniões e valores políticos ocorrida no âmbito familiar, que é permeável a tais assuntos por meio das mídias (e, mais recentemente, pela Internet). Segundo Muxel (2008; 2018), discussões de ordem política penetram continuamente o ambiente íntimo familiar (sobretudo em períodos eleitorais ou de crise), no qual as crianças captam, apreendem e adaptam informações, reações e atitudes dos adultos, em um regime de afetividade, assimilando, ao mesmo tempo, registros e referências afetivas e políticas que influenciam de modo importante as etapas posteriores de socialização política. 
No Brasil, Castro e Grisolia (2016) afirmam que a ausência de estudos sobre política e infância está ligada a uma concepção da subjetividade infantil, que é compreendida majoritariamente como passiva e em processo de formação - portanto, marcada pela incompletude, desconsiderando que as crianças também são sujeitos políticos, "de fala e de direitos", com papéis públicos que devem ser considerados em suas particularidades. Lima (2020), por sua vez, analisa o programa de educação cívica Câmara Mirim - Plenarinho e sua importância para a formação de uma cultura política democrática no Brasil, destacando a necessidade de se ofertar às crianças um ambiente educacional que promova engajamento público efetivo, bem como condições de participação pública em ambientes democráticos, nos quais as crianças possam ouvir e ser ouvidas.

No que tange a importância das relações intergeracionais e, portanto, também da família como instância socializadora nos processos de constituição dos comportamentos políticos, destacam-se, na bibliografia nacional, os estudos sobre a transmissão entre pais e filhos de modos de se relacionar com a política, constextualizados em culturas políticas específicas, tais como na região do ABC Paulista ou na zona sul da cidade de São Paulo (SILVA, 2017; MORENO, 2018). Outros artigos, ainda que não se debrucem especificamente sobre o estudo da instituição familiar, destacam a importância da transmissão familiar na totalidade dos processos de formação do comportamento político (FUKS; PEREIRA, 2011; FUKS, 2011; 2012; SAMPAIO; SIQUEIRA, 2013).

Avançando para a próxima etapa da vida, os temas e perspectivas dos estudos sobre a juventude na literatura brasileira são variados: condições de existência e posição social dos jovens; especificidades da experiência juvenil; família; religião; grupos de pares; escolarização; as mídias e a Internet. Além disso, também são abordados diferentes espaços de participação: partidos, entidades estudantis e movimentos sociais; movimentos religiosos e identitários, como, por exemplo, o movimento LGBTQ+ (OKADO; RIBEIRO; LAZARE, 2018; MORENO, 2018; BRENNER, 2018; GROPPO; BORGES, 2018; BAQUERO; BAQUERO; MORAIS, 2016; TOMIZAKI; DANILIAUSKAS, 2018).

Outro aspecto a ser destacado entre os estudos que assumem a juventude como etapa da vida privilegiada para o entendimento da formação, da compreensão e da relação com a política é a relevância das análises de programas de educação cívica ou educação para a democracia, realizados, de modo preferencial e quase exclusivamente, durante a juventude. Trata-se de estudos que analisam os efeitos da participação nesses programas sobre o comportamento e a participação política dos jovens. Os principais programas analisados são: Parlamento Jovem de Minas Gerais; Parlamento Jovem Brasileiro; Câmara Mirim - Plenarinho; e outros programas de educação para a democracia em vigor no Congresso Nacional. Esses estudos têm em comum a defesa de que a educação (formal ou informal) é fundamental, quiçá o principal meio, para a aquisição de elementos cognitivos que possibilitem a compreensão da política e da democracia, contribuindo, assim, para a solidificação dos regimes democráticos (BARROS, 2016; MARTINS; BARROS, 2018; SAMPAIO; SIQUEIRA, 2013, FUKS; PEREIRA, 2011; FUKS, 2011; 2012, 2014; OLIVEIRA; BIANCHINI, 2017).

Na sequência das etapas da vida, passamos para a vida adulta, quando há maior tendência à estabilização de aprendizados e à consolidação das identidades políticas, o que não significa impossibilidade de mudanças (MUXEL, 2011; 2018). Entre os poucos estudos que abordam de maneira mais aprofundada a vida adulta, destacam-se aqueles que estão voltados para a análise dos processos de formação e transformação dos comportamentos políticos por meio do engajamento em movimentos sociais, especialmente o Movimento dos Trabalhadores Sem Terra (MST) e o Movimento dos Trabalhadores Sem Teto (MTST), bem como para a experiência do voto (TOMIZAKI; CARVALHO-SILVA; SILVA, 2016; RODRIGUES, 2017; BASTOS, 2017; CARVALHO-SILVA, 2018; ALMEIDA, 2017).

$\mathrm{Na}$ sequência, está a velhice, etapa da vida em que as identidades políticas tenderiam a estar formadas e mais fortemente consolidadas. Um fator digno de nota é a quase ausência de estudos que discutam 
comportamentos políticos dos(as) velhos(as) ou seu papel na formação dos modos de se perceber e atuar na política das novas gerações, o que pode indicar, assim como no caso da infância, uma perspectiva limitada em relação às potências política e social da última etapa da vida, que, graças ao aumento da expectativa de vida, torna-se cada vez mais longa. Nesse sentido, é preciso ressaltar dois aspectos desse debate: de um lado, se os processos educativos não estão circunscritos ao ambiente escolar/familar ou a uma única etapa da vida, aprendemos, assimilamos ou ressignificamos opinões e comportamentos políticos em todas as etapas da vida, embora com intensidades diferentes - portanto, também na velhice. Por outro lado, devemos considerar que os(as) velhos(as), por terem vivido experiências em tempos e espaços sociais outros, podem aportar aprendizados importantes para as novas gerações, como o apoio à democracia, fenômeno que foi identificado em trabalhos recentes sobre a América Latina (FUKS; PAULINO; CASALECCHI, 2018).

Esse resultado é instigante, pois contraria a ideia de que os mais jovens teriam maior propensão a desenvolver atitudes democráticas. No caso específico da América Latina, os dados apontam na direção oposta: os mais velhos têm um perfil mais democrático do que os jovens. Uma explicação plausível [...] é que as gerações mais velhas são justamente aquelas que experimentaram as atrocidades militares e as que vivenciaram a luta por eleições diretas, direitos políticos e sociais. Nesse sentido, elas teriam enraizado os valores democráticos de forma mais sólida do que as gerações posteriores, que viveram só na democracia e que não participaram do processo de transição (FUKS; CASALECCHI; RIBEIRO, 2019, p. 21-22).

Novamente, não se trata de buscar os "efeitos puros da idade" ou de uma determinada etapa da vida sobre os comportamentos políticos, mas de compreender tais comportamentos como resultado de uma conjugação entre vários fatores, inclusive históricos e contextuais.

\section{Considerações Finais}

Temos apenas a nossa história e ela não é nossa. José Ortega y Gasset

Assim como nossas histórias não são somente nossas, constituindo parte de histórias mais amplas, que se alongam no tempo e no espaço, em direção ao passado e também ao futuro, nossos modos de se relacionar com o universo da política são também tributários de múltiplas histórias: das histórias das gerações que nos precederam; das histórias vividas no presente, situadas em configurações políticas, econômicas e sociais específicas (e que nos escapam); das histórias que podemos conceber para o futuro (nosso mesmo e das gerações que nos sucederão).

Tendo em vista contribuir para adensar o debate em torno da necessidade de estabelecimento de uma agenda de pesquisa que dê conta da complexidade de tais fenômenos, neste artigo, apresentamos uma proposta de análise da formação e da transformação dos comportamentos políticos na articulação com os processos de transmissão intergeracional de posições sociais, ao longo de diferentes etapas da vida. Portanto, trata-se de uma abordagem de cunho teórico com implicações metodológicas, que se organiza em torno da interrogação sobre o funcionamento dos mecanismos de transmissão e herança que são colocados em movimento na constituição de quadros de percepção e avaliação da realidade, os quais, por sua vez, redundam em determinados modos de interpretar e reagir aos acontecimentos de ordem política. 
Remeter essa discussão para o âmbito das relações intergeracionais significa radicalizar a ideia de que os comportamentos políticos são o resultado de uma complexa transação entre as disposições assimiladas ao longo dos processos de socialização e os desafios que se apresentam pelas conjunturas sociais, econômicas e políticas, em contextos históricos específicos; que impulsionam, ao seu turno, processos de ressocialização e de reflexividade fundados nas avaliações (conscientes e inconscientes) do momento presente, bem como nas possibilidades de constituir expectativas para o futuro.

Vale destacar, finalmente, que assumir essa perspectiva teórica exige também investimentos metodológicos na produção de dados, quantitativos e/ou qualitativos, que articulem dimensões macro e microestruturais na compreensão dos mecanismos de transmissão vivenciados em múltiplas instâncias socializadoras, com destaque para as especificidades em função das posições sociais dos grupos estudados.

\section{Contribuições das Autoras}

Problematização e conceituação: Tomizaki K e Silva MGV; Metodologia: Tomizaki K e Silva MGV; Análise: Tomizaki K e Silva MGV; Redação: Tomizaki K e Silva MGV.

\section{Notas}

1. Segundo Bréchon (2006), opiniões estão relacionadas às ideias, como afirmações ou comentários sobre um dado assunto ou uma tomada de posição sobre um debate em curso na sociedade. Comportamentos, por sua vez, referem-se a atos relacionados à política, como o voto. Por fim, atitudes referem-se a uma disposição mais geral, perene e profunda do que as duas dimensões anteriores - refere-se, sobretudo, a um conjunto de orientações e disposições interiorizadas pelos indivíduos, que fundam suas opiniões e seus comportamentos. Neste artigo, usaremos o termo "comportamento político" para designar esses três níveis da relação com a política.

2. De acordo com Mannheim, a contemporaneidade cronológica não é suficiente para definir o pertencimento a uma geração. Assim, a formação de grupos geracionais pressupõe que os indivíduos que entram, simultaneamente, na vida, participem de acontecimentos e experiências capazes de criar laços entre eles. "Somente um mesmo quadro de vida histórico-social permite que a situação definida pelos nascimentos no tempo cronológico torne-se uma situação sociologicamente pertinente" (MANNHEIM, [1928]1990, p. 52).

3. Segundo Bourdieu, o campo "é um microcosmo, isto é, um pequeno mundo social relativamente autônomo no interior do grande mundo social. Nele se encontrará um grande número de propriedades, relações, ações e processos que se encontram no mundo global, mas esses processos, esses fenômenos, se revestem aí de uma forma particular. É isso o que está contido na noção de autonomia: um campo é um microcosmo autônomo no interior do macrocosmo social. Autônomo, segundo a etimologia, significa que tem sua própria lei, seu próprio nomos, que tem em si próprio o princípio e a regra de seu funcionamento. É um universo no qual operam critérios de avaliação que lhe são próprios e que não teriam validade no microcosmo vizinho. Um universo que obedece a suas próprias leis, que são diferentes das leis do mundo social ordinário" (BOURDIEU, 2011, p. 195).

4. A noção de habitus, retrabalhada em relação às suas origens aristotélico-tomistas, na obra de Bourdieu, cumpre a função de relacionar as dimensões individual e social. Trata-se de um sistema de (pré)disposições adquiridas nos processos de socialização. "Produto da história, o habitus produz as práticas, individuais e coletivas, portanto, da história, conforme os esquemas engendrados pela história; ele garante a presença ativa das experiências passadas 
que, depositadas em cada organismo sob a forma de esquemas de percepção, de pensamento e de ação, tendem, de forma mais segura que todas as regras formais e que todas as normas explícitas, a garantir a conformidade das práticas e sua constância ao longo do tempo" (BOURDIEU, 2009, p. 90).

5. Trata-se de um conceito cunhado por André Singer, que designa uma agenda política de combate à pobreza, a ativação do mercado interno, porém, sem contestação dos interesses do capital, o que conduziu a um realinhamento do eleitorado, aproximando a liderança de Lula com o subproletariado brasileiro (SINGER, 2012; 2018).

6. Embora não seja nosso objetivo discutir a quem caberia a educação política das crianças e adolescentes, vale chamar a atenção para esse debate diante da conjuntura política brasileira, na qual assistimos o avanço do pensamento conservador com investidas contínuas contra uma educação crítica, política e diversa nas escolas, por meio, por exemplo, das tentativas de implementação do projeto Escola sem Partido (PENNA, 2016; SEVERO; GONÇALVES; ESTRADA, 2019).

\section{Referências}

ALMEIDA, R. M. As disputas em torno de direitos como um processo educativo: um estudo de caso sobre a ocupação "Novo Pinheirinho" de Embu das Artes, SP. 2017. 143 f. Dissertação (Mestrado em Educação) Faculdade de Educação, Universidade de São Paulo, São Paulo, 2017.

ALWIN, D. F.; FELMLEE, D. H.; KREAGER, D. A. (eds.). Social networks and the life course. Integrating the development of human lives and social relational networks. [S. 1.]: Springer, 2018.

ATTIAS-DONFUT, C. Sociologie des générations: l'empreinte du temps. Paris: Universitaire de France, 1988.

ATTIAS-DONFUT, C. Rapports de générations: transfert intrafamiliaux et dynamique macrosociale. Revue Française de Sociologie, Paris, v. 41, n. 4, p. 643-684, 2000. https://doi.org/10.2307/3322701

ATTIAS-DONFUT, C.; WOLFF, F. C. La dimension subjective de la mobilité sociale. Population, Paris, a. 56, n. 6, p. 919-958, 2001. https://doi.org/10.2307/1534747

BARROS, A. T. Educação e legislação: desafios para o aprendizado político e a cultura democrática. Educação \& Sociedade, Campinas, v. 37, n. 136, p. 861-872, set. 2016. https://doi.org/10.1590/es0101-73302016112841

BAQUERO, M.; BAQUERO, R. V. A.; MORAIS, J. A. Socialização política e Internet na construção de uma cultura política juvenil no sul do Brasil. Educação \& Sociedade, v. 37, n. 137, p. 989-1008, 2016. https://doi. org/10.1590/es0101-73302016166022

BASTOS, P. N. MST e Escola Nacional Florestan Fernandes: formação, comunicação e socialização política. Intercom: Revista Brasileira de Ciências da Comunicação, São Paulo, v. 40, n. 2, p. 129-142, ago. 2017. https:// doi.org/10.1590/1809-5844201728

BERNARDIA, L.; HUININKB, J.; SETTERSTEN JR., R. The life course cube: a tool for studying lives. Advances in Life Course Research, Oxford, v. 41, p. 1-13, sep. 2019. https://doi.org/10.1016/j.alcr.2018.11.004

BORGES, A.; VIDIGAL, R. Do lulismo ao antipetismo? Polarização, partidarismo e voto nas eleições presidenciais brasileiras. Opinião Pública, São Paulo, v. 24, n. 1, p. 53-89, 2018. https://doi. org/10.1590/1807-0191201824153 
BOURDIEU, P. Questions de politique. Actes de la Recherche en Sciences Sociales, Paris, v. 16, p. 55-89, sep. 1977.

BOURDIEU, P. A economia das trocas simbólicas. São Paulo: Perspectiva, 2004.

BOURDIEU, P. O poder simbólico. Rio de Janeiro: Bertrand Brasil, 2005.

BOURDIEU, P. O senso prático. Petrópolis: Vozes, 2009.

BOURDIEU, P. O campo político. Revista Brasileira de Ciência Política, Brasília, n. 5, p. 193-216, jan.-jul. 2011. https://doi.org/10.1590/S0103-33522011000100008

BOURDIEU, P.; WACQUANT, L. Réponses. Paris: Seuil, 1992.

BOY, D. Origine sociale et comportement politique. Revue Française de Sociologie, Paris, v. 19, n. 1, p. 73-102, 1978. https://doi.org/10.2307/3320954

BRÉCHON, P. Valeurs de gauche, valeurs de droite et identités religieuses en Europe. Revue Française de Sociologie, Paris, v. 47, n. 4, p. 725-753, 2006. https://doi.org/10.3917/rfs.474.0725

BRENNER, A. K. Do potencial à ação: o engajamento de jovens em partidos políticos. Pro-Posições, Campinas, v. 29, n. 1, p. 239-266, abr. 2018. https://doi.org/10.1590/1980-6248-2016-0120

CARVALHO-SILVA, H. H. A dimensão educativa da luta de mulheres por moradia no Movimento dos Trabalhadores Sem Teto de São Paulo. 2018. 219 f. Tese (Doutorado em Educação) - Faculdade de Educação, Universidade de São Paulo, São Paulo, 2018.

CASTRO, L. R.; GRISOLIA, F. S. Subjetivação pública ou socialização política? Sobre as articulações entre o "político" e a infância. Educação \& Sociedade, Campinas, v. 37, n. 137, p. 971-988, dez. 2016. https://doi. org/10.1590/es0101-73302016167363

DARMON, M. La socialisation. Paris: Armand Colin, 2015.

DIAS, A. L.; KERBAUY, M. T. M. Engajamento cívico e escolaridade superior: as eleições de 2014 e o comportamento político dos brasileiros. Revista de Sociologia e Política, Curitiba, v. 23, n. 56, p. 149-181, 2015. https://doi.org/10.1590/1678-987315235607

DUBAR, C. La socialisation. Construction des identités sociales et professionnelles. Paris: Armand Colin, 2002.

ELDER JR., G. H.; GIELE, J. Z. (eds.). The craft of the life course research. New York: The Guilford Press, 2009. $372 \mathrm{p}$.

FERRAZ, S. E. Voto e classe: notas sobre alguns estudos recentes. Opinião Pública, São Paulo, v. 15, n. 2, p. 451-477, 2009. https://doi.org/10.1590/S0104-62762009000200007

FUKS, M. Efeitos diretos, indiretos e tardios: trajetórias da transmissão intergeracional da participação política. Lua Nova, São Paulo, n. 83, p. 145-178, 2011. https://doi.org/10.1590/S0102-64452011000200006

FUKS, M. Atitudes, cognição e participação política: padrões de influência dos ambientes de socialização sobre o perfil político dos jovens. Opinião Pública, São Paulo, v. 18, n. 1, p. 88-108, jun. 2012. https://doi. org/10.1590/S0104-62762012000100005 
FUKS, M. Explicando os efeitos de programas de socialização política: a experiência do Parlamento Jovem no Brasil. Opinião Pública, São Paulo, v. 20, n. 3, p. 425-449, dez. 2014. https://doi. org/10.1590/1807-01912014203425

FUKS, M.; CASALECCHI, G. A. Expandindo o conceito de competência política: conhecimento político e atitudes democráticas na América Latina. Revista de Sociologia e Política, Curitiba, v. 26, n. 68, p. 61-74, 2018. https:// doi.org/10.1590/1678987318266802

FUKS, M. et al. Qualificando a adesão à democracia: quão democráticos são os democratas brasileiros? Revista Brasileira de Ciência Política, Brasília, n. 19,p. 199-219, abr. 2016. https://doi.org/10.1590/0103-335220161908

FUKS, M.; PAULINO, R. O.; CASALECCHI, G. A. Socialization and political regimes: the impact of generation on support for democracy in Latin America. Brasilian Political Science Review, São Paulo, v. 12, n. 1, p. 1-22, 2018. https://doi.org/10.1590/1981-3821201800010001

FUKS, M.; PEREIRA, F. B. Informação e conceituação: a dimensão cognitiva da desigualdade política entre jovens de Belo Horizonte. Revista Brasileira de Ciências Sociais, São Paulo, v. 26, n. 76, p. 123-143, jun. 2011. https://doi.org/10.1590/S0102-69092011000200007

FUKS, M.; CASALECCHI, G. A.; RIBEIRO, E. A. Determinantes contextuais da coesão do sistema de crenças democrático: evidências a partir da América Latina. Revista Brasileira de Ciências Políticas, São Paulo, Brasília, n. 28, p. 7-32, 2019. https://doi.org/10.1590/0103-335220192801

GIMENES, E. R.; BORBA, J. Adesão à democracia e apartidarismo na América Latina: análise multidimensional. Revista Mediações, Londrina, v. 24, p. 167-183, 2019. https://doi.org/10.5433/2176-6665.2019v24n3p167

GROPPO, L. A.; BORGES, L. F. Grupo evangélico na universidade: práticas formativas, identidade religiosa e relações políticas. Religião \& Sociedade, Rio de Janeiro, v. 38, n. 3, p. 173-196, dez. 2018. https://doi. org/10.1590/0100-85872018v38n3cap08

LAGROYE, J. La socialisation politique. La pensée vivante d'Annick Percheron. Revue Française de Science Politique, Paris, a. 44, n. 1, p. 129-136, 1994.

LAHIRE, B. Le travail sociologique de Pierre Bourdieu. Dettes e critiques. Paris: La Découverte, 2001.

LIMA, A. M. P. Limites da tolerância na educação para a democracia: o programa Câmara Mirim - Plenário. Educação e Pesquisa, São Paulo, v. 46, e213265, 2020. https://doi.org/10.1590/s1678-4634202046213265

MANNHEIM, K. (1928). Le problème des générations. Paris: Nathan, 1990.

MARTINS, L. M.; BARROS, A. T. Juventude e educação para a democracia: relatos de egressos do Parlamento Jovem Brasileiro. Revista de Sociologia e Política., v. 26, n. 66, p. 49-78, jun. 2018. https://doi. org/10.1590/1678-987318266603

MAYER, N. In memoriam: l'apport d'Annick Percheron à la sociologie. Revue Française de Sociologie, Paris, v. 1, n. 34, p. 125-133, 1993.

MORENO, G. G. Juventude e vida associativa nas periferias de São Paulo. Caderno CRH, Salvador, v. 31, n. 84, p. 581-599, dez. 2018. https://doi.org/10.1590/s0103-49792018000300010

MUXEL, A. Moi, toi et la politique: amour et convictions. Paris: Seuil, 2008. 
MUXEL, A. La politique au fil de l'âge. Paris: Presses de Sciences Po, 2011. 312 p.

MUXEL, A. La politique dans la chaîne des générations. Quelle place et quelle transmission? Revue de l'OFCE, Paris, v. 2, n. 156, p. 29-41, 2018. https://doi.org/10.3917/reof.156.0029

MUXEL, A.; PERCHERON, A. Histoires politiques de famille: premières illustrations. Life Stories. Paris: Presses de Science Po, 1985. v. 1.

NICO, M. Transição biográfica inacabada. Transições para a vida adulta em Portugal e na Europa na perspectiva do curso de vida. 2011.361 f. Tese (Doutorado em Sociologia) - Iscte, Instituto Universitário de Lisboa, Lisboa, 2011.

OKADO, L. T. A.; RIBEIRO, E. A.; LAZARE, D. C. M. Partidarismo, ciclos de vida e socialização política no Brasil. Pro-Posições, Campinas, v. 29, n. 1, p. 267-295, abr. 2018. https://doi.org/10.1590/1980-6248-2016-0063

OLIVEIRA, M. A.; BIANCHINI, P. Educação Política no Brasil e na Itália, duas histórias, muitos problemas comuns. História da Educação, Porto Alegre, v. 21 n. 52, p. 274-294, maio-ago., 2017. https://doi. org/10.1590/2236-3459/69712

ORTEGA y GASSET, J. (1923). El tema de nuestro tiempo. Madrid: Revista de Occidente, 1981.

PEIXOTO, V.; RENNÓ, L. Mobilidade social ascendente e voto: as eleições presidenciais de 2010 no Brasil. Opinião Pública, São Paulo, v. 17, n. 2, p. 304-332, nov. 2011. https://doi.org/10.1590/ S0104-62762011000200002

PENNA, F. A. Programa "Escola sem Partido": uma ameaça à educação emancipadora. In: GABRIEL, C; MONTEIRO, A.; MARTINS, M. (org.), Narrativas do Rio de Janeiro nas aulas de história. Rio de Janeiro: Mauad, 2016. p. 43-58.

PERCHERON, A. L'univers politique des enfants. Paris: Armand Colin/Presses de la Fondation Nationale de Science Politique, 1974.

PERCHERON, A. Socialisation et tradition: transmission et invention du politique. Pouvoirs, 1987. p. 43-51. (n. 42: La tradition politique.)

PERCHERON, A. Histoires politiques de famille: premières illustrations. Life Stories. Paris: Presses de Sciences Po, 1988. v. 4.

PERCHERON, A. La socialisation politique. Paris: Armand Colin, 1993.

PETERS, G. Habitus, reflexividade e neo-objetivismo na teoria da prática de Pierre Bourdieu. Revista Brasileira de Ciências Sociais, São Paulo, v. 28, n. 83, p. 47-71, out. 2013. https://doi.org/10.1590/ S0102-69092013000300004

PEUGNY, C. La mobilité sociale descendante et ses conséquences politiques: recomposition de l'univers de valeurs et préférence partisane. Revue Française de Sociologie, Paris, v. 47, n. 3, p. 443- 478, 2006. https:// doi.org/10.3917/rfs.473.0443

PEUGNY, C. La dynamique générationnelle de la mobilité sociale. Idées Économiques et Sociales, Paris, v. 1, n. 175, p. 18-24, 2014. https://doi.org/10.3917/idee.175.0018 
RENNÓ, L.; TURGEON, M. A psicologia política das classes sociais no Brasil: atributos das atitudes políticas por estratificação e mobilidade social. Dados, Rio de Janeiro, v. 59, n. 1, p. 11-52, mar. 2016. https://doi. org/10.1590/00115258201670

RENNÓ, L.; BORBA, J. Tolerância política no Brasil recente: evolução de indicadores e condicionantes. Caderno CRH, Salvador, v. 32, n. 87, p. 641-657, set. 2019. https://doi.org/10.9771/ccrh.v32i87.23749

RIBEIRO, E. Sentimentos partidários e atitudes políticas entre os brasileiros. Opinião Pública, São Paulo, v. 17, n. 2, p. 333-368, 2011. https://doi.org/10.1590/S0104-62762011000200003

RIBEIRO, E.; CARREIRÃO, Y.; BORBA, J. Sentimentos partidários e antipetismo: condicionantes e covariantes. Opinião Pública, São Paulo, v. 22, n. 3, p. 603-637, 2016. https://doi.org/10.1590/ 1807-01912016223603

ROCHA, E. F. Espaço social e estrutura de classes em regiões metropolitanas brasileiras. Sociedade e Estado, Brasília, v. 33, n. 3, p. 779-801, 2018. https://doi.org/10.1590/s0102-6992-201833030006

ROCHA, E. F. Atitudes políticas e mundos semânticos: um estudo qualitativo sobre a racionalidade aquém das ideologias políticas. Civitas - Revista de Ciências Sociais, Partenon, v. 20, n. 1, p. 85-97, 2020. https:// doi.org/10.15448/1984-7289.2020.1.29912

RODRIGUES, F. C. Educação e luta pela terra no Brasil: a formação política no Movimento dos Trabalhadores Rurais Sem Terra. Educação \& Sociedade, Campinas, v. 38, n. 138, p. 27-44, jan. 2017. https://doi.org/10.1590/ es0101-73302017165251

SAMPAIO, T.; SIQUEIRA, M. Impacto da educação cívica sobre o conhecimento político: a experiência do programa Parlamento Jovem de Minas Gerais. Opinião Pública, São Paulo, v. 19, n. 2, p. 380-402, nov. 2013. https://doi.org/10.1590/S0104-62762013000200006

SAMUELS, D. As bases do petismo. Opinião Pública, São Paulo, v. 10, n. 2, p. 221-241, 2004. https://doi. org/10.1590/S0104-62762004000200002

SCHLEGEL, R. Educação e comportamento político. Os retornos decrescentes da escolarização brasileira recente. 2010. 324 f. Tese (Doutorado em Ciências Políticas) - Faculdade de Educação, Universidade de São Paulo, São Paulo, 2010.

SEVERO, R. G.; GONCALVES, S. R. V; ESTRADA, R. D. A rede de difusão do movimento Escola Sem Partido no Facebook e Instagram: conservadorismo e reacionarismo na conjuntura brasileira. Educação \& Realidade, Porto Alegre, v. 44, n. 3, 2019. https://doi.org/10.1590/2175-623684073

SINGER, A. Os sentidos do Lulismo. Reforma gradual e pacto conservador. São Paulo: Companhia das Letras, 2012.

SINGER, A. O lulismo em crise. Um quebra-cabeças do período Dilma (2011-2016). São Paulo: Companhia das Letras, 2018.

SINGLY, F. A Apropriação da herança cultural. Educação \& Realidade, Porto Alegre, v. 34, n. 1, p. 9-32, 2009.

SILVA, T. M. Nem tão "Flamengo": questões de posição e o voto no Brasil. Revista de Sociologia e Política, v. 27, n. 69,2019 . https://doi.org/10.1590/1678-987319276905 
SILVA, M. G. V. Ferrazópolis: um bairro, duas gerações e a política. 2017. 233f. Tese (Doutorado em Educação) - Faculdade de Educação, Universidade de São Paulo, São Paulo, 2017.

SILVA, M. G. V.; TOMIZAKI, K. O sonho de ser metalúrgico: dimensões da vivência juvenil no ABC Paulista. Linhas Críticas, Brasília, v. 22, p. 86-109, 2016. https://doi.org/10.26512/lc.v22i47.4783

TERRON, S. L.; SOARES, G. A. D. As bases eleitorais de Lula e do PT: do distanciamento ao divórcio. Opinião Pública, São Paulo, v. 16, n. 2, p. 310-337, 2010. https://doi.org/10.1590/S0104-62762010000200002

TOMIZAKI, K. Abordagem geracional no estudo das relações entre família e escola. In: ROMANELLI, G.; NOGUEIRA, M. A.; ZAGO, N. (orgs.). Família \& Escola - novas perspectivas de análise. Petrópolis: Vozes, 2013. p 83-106.

TOMIZAKI, K.; CARVALHO-SILVA, H. H.; SILVA, M. G. V. Socialização política e politização entre famílias do movimento dos trabalhadores sem teto. Educação \& Sociedade, Campinas, v. 37, n. 137, p. 935-954, 2016. https://doi.org/10.1590/es0101-73302016166488

TOMIZAKI, K.; DANILIAUSKAS, M. A pesquisa sobre educação, juventude e política: reflexões e perspectivas. Pro-Posições, Campinas, v. 29, n. 1, p. 214-238, abr. 2018. https://doi.org/10.1590/1980-6248-2016-0126

VANDENBERGHE, F. Os pós-bourdieusianos: retrato de uma família disfuncional. In: VANDENBERGHE, F.; VÉRAN, J. (orgs.). Além do habitus - Teoria social pós-bourdieusiana. Rio de Janeiro: 7Letras, 2016.

VANDENBERGHE, F.; VÉRAN, J. (orgs.). Além do habitus - Teoria social pós-bourdieusiana. Rio de Janeiro: 7Letras, 2016.

\section{Sobre as Autoras}

KImi Tomizaki é professora de Sociologia na Faculdade de Educação da Universidade de São Paulo (USP) e no Programa de Pós-graduação em Educação da mesma unidade (PPGE/FEUSP). Mestre e Doutora em Educação pela Universidade Estadual de Campinas (Unicamp) e Pós-doutora pelo Centre de Recherches Sociologiques et Politiques, de Paris. Autora do livro Ser Metalúrgico no ABC Paulista: Transmissão e Herança da Cultura Operária entre Duas Gerações de Trabalhadores (Centro de Memória da Unicamp/Arte Escrita Editora/FAPESP).

Maria Gilvania Valdivino Silva é investigadora integrada no Centro de Investigação e Estudos de Sociologia do Instituto Universitário de Lisboa. Graduada em História pela Universidade Estadual Paulista (Unesp) mestre e doutora em Educação pela Faculdade de Educação da Universidade de São Paulo (FEUSP). Desenvolve pesquisas na área de Sociologia e Educação e atua principalmente sobre as temáticas das Gerações, Famílias, Socialização política, Politização, Classes populares e ABC Paulista.

Recebido: 07 ago. 2020 Aceito: 19 nov. 2020 